\title{
Factors Influencing the Utilisation of Public and Private Primary Health Care Services in Riyadh City
}

\author{
SAAD ABDUllah AL-GHANIM \\ Assistant Professor \\ Department of Public Administration \\ College of Administrative Sciences \\ King Saud University, Riyadh, Saudi Arabia
}

( Received 09.09.1425H, and Accepted 11.01.1426H )

\begin{abstract}
Objective: To determine the variables which predict the utilisation of public and private primary health care services, incorporating a number of individual and provider-related variables which are thought to influence the utilisation of these services.

Methods: The study employed a self-administered questionnaire to collect data from patients attending both public PHC centres and private dispensaries (or outpatient clinics) in Riyadh city. The questionnaire was designed to collect data on a number of variables related both to health services users and providers. Descriptive statistics and binary logistic regression were used to determine the significant variables which may influence the utilisation of these services.

Results: The results show that a number of patient-related variables (income, health status, education, gender, the presence of health insurance and nationality) and provider-related variables (location of the health facility, waiting time, the availability of ancillary services, opening hours and the availability of specialised doctors) were statistically significant in identifying the variables which influence the utilisation of both public PHC centres and private outpatient clinics.
\end{abstract}

Conclusion: The study highlights the significant factors which prompt patients to utilise private outpatient clinics despite the availability of free public PHC centres in Saudi Arabia. Understanding these factors by health policy makers is important in the provision and the utilisation of primary health care services in the Kingdom. The study recommends significant areas for future research. 


\section{Introduction}

In 2002, there were more than 98 million visits to all health care facilities in the Kingdom, of which 53.5 million visits $(55 \%)$ were made to the public PHC centres. The total number of visits made to the private sector comprised more than $18 \%$ of the total visits. Analysing the utilisation of public PHC centres and private outpatient clinics contributes to an understanding of the factors driving the development of both health care sectors. Theoretical considerations suggest that utilisation of such health facilities may be influenced by a range of factors including those which relate both to the individuals using the service and the providers of these services.

As part of a health care system, primary health care has enormous importance in the delivery of health care. It has this importance because the primary health care facility is the first point of care and a major conduit for the delivery of health care to a significant proportion of the population. In 1978, the primary health care concept adopted at the Alma Ata conference was recognised by the Saudi Ministry of Health (MOH) and became a fundamental part of its policy (Sebai, 1987).

In Saudi Arabia, the provision of health services is divided between the government (MOH and other governmental organisations) and the formal private sector. According to the $\mathrm{MOH}$ annual reports $(\mathrm{MOH}, 2002)$, there are 1,792 public primary health care centres scattered throughout the kingdom. While $\mathrm{MOH}$ primary health care centres provide preventive and curative health services and are considered as the normal entry point for treatment in the health care system, health services provided by the private sector are curative in nature and vary from basic medical care to highly organised specialist services (Al-Mazrou et al., 1995).

The government in its previous national development plans is encouraging the private sector to take a much greater role in the delivery of health care services in Saudi Arabia. This is stimulated by interest-free government loans, subsidies for the construction of medical facilities, the exemption of medical apparatus from customs duty and the government purchase of services from the private sector. This encouragement has led to the expansion of private-sector providers in the Kingdom (Umeh, 1994). MOH reports show that facilities available in the private sector include specialised hospitals, general hospitals, dispensaries, private clinics, polyclinics and pharmacies.

According to the MOH annual statistics (MOH, 2002, pp.159-160), the total number of private dispensaries in the Kingdom is 1,046, of which 370 dispensaries (35.4\%) are present in Riyadh and 151 dispensaries $(14.4 \%)$ are present in Jeddah. The total number of private clinics and polyclinics is 815 , of which 293 clinics $(35.9 \%)$ are present in Riyadh while 285 clinics $(34.9 \%)$ are present in Jeddah. The total number of polyclinics is 277 . Of these, 110 (39.7\%) polyclinics are present in Riyadh and 86 polyclinics $(31 \%)$ are present in Jeddah. The estimated total number of physicians in the private sector is estimated by 11,298 , of which 1,369 (including dentists) are working in private clinics and polyclinics. 
Despite the fact that the $\mathrm{MOH}$ provides free health care at all its primary health care centres, the provision of health care in the private sector's outpatient clinics, where patients have to pay for their health directly or indirectly, is in direct competition with the MOH primary health care centres. Shortell (1988) reports that the ability to provide accessible and cost-effective health services to patients depends on a thorough understanding of the factors associated with the use of health services, in particular the factors which can be manipulated to improve the provision of care. Further, a better understanding of the factors which influence people's utilisation and choice of health care providers would potentially provide health policy makers with useful information which would equip them to plan better in both the public and private health care sectors and consequently to use resources more efficiently.

\section{Objectives}

With the growth of public and private health care facilities in the Kingdom, it is important to assess the importance of explanatory factors, which determine the utilisation of these facilities. In particular, it is important to determine how the variables of the patients and the health providers influence the use of these services. If accessibility, availability and quality issues, for example, are being compromised by these facilities, it calls for the re-evaluation of policy measures to redefine their role, growth and coverage and to seek appropriate interventions to ensure that these facilities are more accessible, available and quality-focused and better able to meet the needs of patients. A search of the literature suggests that such studies in the Kingdom are scarce.

Accordingly, the present study was conducted with the main objective of determining the variables important in using public PHC centres and private outpatient clinics incorporating a number of patient-related and provider-related variables which were thought to influence the use of these two types of health care facilities. It provides an empirically based contribution to understanding the variables which influence the decision-making process in choosing the type of health care facility (public vs. private) according to the conceptual framework shown in Fig. 1. This study complements earlier studies and thus it leads health planners to a better understanding of the factors driving the development of the private sector and knowledge of the factors associated with health-seeking behaviour.

This paper is organised as follows. The section below presents a brief review of the literature on factors influencing the utilisation of public and private health care facilities. The second section presents the methodology of data collection and analysis. Results are presented and discussed in the third and fourth sections. The last section concludes the paper.

\section{Review of the Literature}

A great quantity of literature concerned with the utilisation of health facilities has emerged over a long period of time in the developed countries. Al-Doghaither et al., (2003) report that in the societies of the developing world, the set of determinant variables for the utilisation of health services seems to be more complex than in the developed countries and additional factors are involved due to cultural differences, which include the different concepts of illness and health behaviour and different socio- 
demographic characteristics. Benyoussef and Wessen (1974) stress the scarcity of research in developing countries and argue that data on the use of health services in these countries is subject to substantially greater error than is the case with the data from developed countries.

Independent variables

Dependent variable

$\underline{\text { Individual-related variables }}$

Socio-demographic variables

Gender

Age

Nationality

Marital status

Educational level

Employment status

Family income

Health-related variables

Registration with public PHC centre

Presence of chronic illness

Perceived health status

Health insurance

\section{$\underline{\text { Provider-related variables }}$}

Accessibility variables

Location of the health facility

Waiting time in health facility

Working hours of the health facility

Availability variables

Ancillary services

Modern equipment

Specialised doctors

Information about patient's health

Qualified health staff

Quality-related variables

Reputation of the health facility

Cleanliness and tidiness

Internal organisation and procedures

Staff courtesy and friendliness

Previous experience (impression)

Fig. 1. Conceptual model of factors influencing the utilisation of public PHC centres and private outpatient clinics. 
In general, research on the use of health care services and facilities is associated with medical, social and behavioural sciences and also with health economics (Purola, 1972). The use of health services has been accounted for in terms of patients' personal factors (health or illness, symptoms, knowledge and understanding, beliefs, etc.), social factors (socio-demographic factors, family factors, etc.) and factors related to the health care system (distance, availability, accessibility, costs, etc.) (McKinlay, 1972; Mechanic, 1979). Levels of utilisation, however, are far from equal, either socially or geographically (Andersen, 1995). These variations are highly important and may directly affect health, both in terms of morbidity and perceived health. In their article, Field and Briggs (2001) report that differences in health care utilisation are thus an important consideration in epidemiological research and also important for policy and planning reasons.

Various conceptual models have been developed by different research bodies to operationalise the complex and multi-dimensional issues of health facilities use. These multi-factorial models offer some theoretical frameworks to be used in the research on the use of health care services and facilities. For example, the Behavioural Model (Andersen and Newman, 1973) and the Health Belief Model (HBM) (Rosenstock, 1966) were among the well-known models which were developed to explain the use of health services and facilities.

According to Andersen and Newman (1973), paying a visit to a health facility is determined by three sets of factors: (1) predisposing factors such as age, gender, race/ethnic group and social status; (2) enabling factors include conditions that facilitate or inhibit the use of health services such as insurance coverage, income, distance to the health centre; availability of regular source of care and, (3) need or health status variables which may include perceived need and urgency, level of distress and presence of psychiatric co-morbidity.

The health belief model (HBM) suggested by Rosenstock (1966) assumes that consumer attitudes and beliefs are important determinants of health action. Leavitt (1979) reports that, within this framework, beliefs concerning four sets of variables are used to account for variations in health care utilisation when cues to action, such as symptoms, are present. They are the individual's view of his/her own vulnerability to illness, his/her beliefs about the severity of that illness defined either in terms of physical harm or interference with social functioning, his/her perception of benefits associated with actions to reduce the level of threat or vulnerability and his/her evaluation of potential barriers associated with the proposed action which can be physical, psychological or financial.

McKinlay (1972) reports that other types of models of health services utilisation behaviour have been proposed in the health services literature, among them economic models, socio-demographic model, geographic model, social-psychological model, socio-cultural model and the organisational model. Galvin and Fan (1975), however, argue that regardless of the model used, all studies face the common problems of classification of health services utilisation, finding operational indices to measure each type of use and finding predictors of and explanation for various types of use. 
Comparison of the variables in various different models used in studies on use of health-care services reveals that there is a large overlap in the variables used in the models (Cummings et al., 1980). Furthermore, findings of studies reporting on the use of health facilities are inconsistent and the contributing factors vary from one study to another, perhaps because of the varying in methodologies used, differing medical care systems, different time periods and the rhetoric of interpretation.

Wan and Soifer (1974) summarised the models which were used to explain the use of health services into three major approaches. The first, used individual attributes, incorporates social and behavioural variables to predict utilisation behaviour. For example, the above-mentioned Rosenstock's health-belief model, which suggests that the readiness to take health action is determined by perceived susceptibility and severity of a health problem, perceived benefits and barriers to taking action and cause which instigate appropriate behaviour, exemplifies this approach. The second approach variables derived from organisational, economic, and ecological frameworks. The concepts of service availability, coordination, accessibility, and methods of financing refer to ecological and functional relationships between economic or community resources and the recipients of services. The third approach assumes that use behaviour is a joint function of both personal attributes and organisational factors. It emphasises that the study of use of services has to be carried out with explicit concern for the ecological and organisational contexts in which health related behaviours occur (Bice and White, 1969).

Despite criticisms directed to these models in a number of studies (Davidson, 1978; Wolinsky, 1978; Safer et al., 1979; White-Means and Thornton, 1989), Wolinsky (1978) reports that one of the promising developments in research on health service utilisation is the effort to construct more complex causal models of the entire health care delivery system. Moreover, by using models, attempts have been made to organise the many different determining factors into one explanatory concept.

It could be argued that the most important factors in affecting an individual 's use of health facilities in any given country do not necessarily have the same significance in other countries because of the differences in environment, socio-cultural aspects, belief systems, the availability of health facilities and technology, differences in levels of knowledge about illness and disease, which all differ between one country and another. Because of such differences, caution must be exercised in generalising findings from one country to another. That is, the findings of studies reporting on the use of health facilities are inconsistent and the contributing factors vary from one study to another, perhaps because of the varying methodologies used, differing medical care systems, different time periods and the rhetoric of interpretation.

In developing countries, there are at present few empirical studies describing the relationship between the utilisation of public or private health care services and a range of factors relating both to patients and to health services providers. Gulliford and Mahabir (2001) report that this is perhaps not surprising as some of these variables are both difficult to measure and inter-related. 
In Saudi Arabia, there is little information available concerning the extent of private health care provision and use, but the importance of the private sector appears to be increasing. Three studies were found on the choice between public and private health care facilities and similar results were inferred. The study conducted by Al-Doghaither et al., (2003) investigates the factors influencing patient choice when selecting a hospital. The study finds that the main factors associated with choosing a hospital were medical services, accessibility, age, sex and education. Using a self-administered questionnaire, Saeed (1998) examines the hospital-related and attitudinal dimensions which influence a patient's choice of hospital and reports that the choice of hospital is influenced by socio-demographic variables as well as hospital attributes. Finally, AlOmar and Saeed (1999) look at the factors influencing the use of public and private primary health care centres and conclude that the source of payment, availability of other sources of income, distance between residence and primary health care provider, education, preference for a doctor of the same gender, preference for a Saudi doctor and the perceived quality of medical staff were the most influential factors in discriminating between the users of public and private health care facilities.

In his study, Andaleeb (2000) compares the quality of services provided by public and private facilities in Bangladesh and reports that, because private health facilities depend on income from the customer, they will be more inclined than public hospitals are to provide more accessible, available and quality-focused care and to meet patients ' needs better. By doing so, they will not only be able to build a body of satisfied and loyal clients who will revisit the same facility for future needs; the clients will also serve as a source of referrals to recommend the private facilities to friends and family, thereby sustaining the long-term viability of private facilities. When it comes to public facilities, however, the author states that there is little or no market incentive to motivate the staff to take extra initiatives or make more effort to improve the condition of patients and ameliorate their suffering. Andaleeb notes that government support and funding assures these facilities of their survival. Harsh as this may sound, the evidence in media reports of their lack of responsiveness, dedication or quality assurance is often stark. This suggests that their service quality will be rated lower than that of the private facilities (Andaleeb, 2000).

\section{Methods}

\section{Design}

The study design is based on the conceptual model shown in Fig. 1. The proposed model defines two groups of independent variables - namely, patient-related variables and provider-related variables - which may have an influence on the dependent variable. The dependent viable is the utilisation of health care facility and was dichotomised as a public PHC centre and private outpatient clinic. These variables were drawn from the literature on the use of the health services as well as from the pilot study conducted before the main survey of the study. It should be noted, however, that the objective of this study was not to 'explain' some modalities of using public and private health services but to identify, if they existed, some variable associated with the way in which people use these health care settings. 


\section{Subjects}

The study was conducted in three health care facilities in Riyadh City. Of these, one is a large public PHC centre and the other two are private dispensaries (outpatient clinics). These sites were chosen to make the total sample as representative of the community as possible. The study population comprised adult individuals (18 years of age and older) who presented to these health care facilities between 8:00 a.m. and 6:00 p.m. during a two-week period in August 2004. A stratified random sampling was used in order to collect data from both types of health services users. 500 questionnaires were distributed (250 in the public PHC centre and 250 in the private dispensaries).

\section{Data Collection}

This is an analytical study using a self-administered questionnaire (Arabic and English versions). The questionnaire was designed to elicit information on different variables which serve the purpose of the study. The questionnaire was divided into two sections. Eleven questions on the patient-related variables including socio-demographic variables (gender, age, nationality, educational level, marital status, employment status and income) and health-related variables (registration with a public PHC centre, perceived health status, presence of chronic illness and whether the patient has health insurance).

In the provider-related variables, patients were asked to rate the importance of the 13 items which influenced their choice of health care facility to attend. Patients were asked to use a scale of 1-4 (with $1=$ Not important at all and $4=$ Very important). These items cover aspects of accessibility variables (location of the health facility, length of waiting time in health facility, opening or working hours), availability variables (availability of medical equipment, availability of specialised doctors, availability of information about the patient's health, availability of qualified health staff and availability of ancillary services) and quality variables (reputation of the health facility, cleanliness, internal organisation and procedures, staff courtesy and previous impression). Many of the survey questions were drawn from previous studies in the literature.

A number of steps were taken to increase the content validity of the questionnaire. Firstly, a review of the relevant literature was carried out in order to select some variables which may have influenced the patient's choice of the type of health care facility. Secondly, the questionnaire was pre-tested in a pilot survey of 30 respondents to ensure that the wording, format, length, sequencing of questions and range of the scales were appropriate. Finally, an academic panel of 3 staff reviewed the questionnaire and made comments and suggestions. In the light of this feedback and the outcome of the pilot study, a few questions were reformulated and others were added (or excluded). The pilot survey questionnaires were not included in the main study.

The covering letter of the questionnaire outlines the title and the purpose of the study, and the status and identity of the researcher. Patients were informed about the importance of the study and were encouraged to participate. A guarantee of confidentiality was mentioned both verbally as well as in the covering letter and the respondents were not asked to identify themselves. 


\section{Analyses}

For the purpose of this study, descriptive statistics (frequency distribution and percentages) and multivariate analyses were employed. In order to carry out the latter, binary logistic regression was used to examine the combined effects of the independent variables and to determine the relative importance of the factors which may have an influence on the utilisation of health care facilities. In the analysis, all the independent variables were entered against the dependent variable (the utilisation of a public PHC centre $v s$. a private outpatient clinic). This determined which variables were statistically significant as well as the total amount of variance which may be explained by all of the variables in the regression. The binary logistic regression has been found to be a reliable statistical method for studying group differences on several independent variables simultaneously and is one of the most appropriate techniques for classifying and predicting objects into one of two clearly defined groups (Taeq, 1997).

Thus, the general hypothesis for this study suggests that the use of the type of health care facility (public $v s$. private) may be influenced by a range of factors relating to both the individuals who seek health care and the providers of such health care (see Fig. 1). Questionnaire responses were coded, entered and analysed using the Statistical Package for Social Sciences (SPSS) for Windows.

\section{Results}

Of the 500 questionnaires distributed, 445 (89\%) were returned. Of these, 35 questionnaires were excluded because of missing responses. Thus, only 410 questionnaires (202 and 208 in the public PHC centre and private outpatient clinics respectively) were fully completed and thus valid for the analysis methodology employed in this study. Therefore, the response rate was $82 \%$.

\section{Descriptive Analysis}

Table 1 shows the general profile of respondents in the study sample. As regards the socio-demographic characteristics, the sample consisted of 231 males $(56.3 \%$, mean age 42 , range 18-81) and 179 females (43.7\%, mean age 47, range 18-90). Thirty-six per cent of the respondents were 40 years old or younger. Three-quarters of the respondents $(76.6 \%)$ were Saudi nationals. More than two-thirds $(67.3 \%)$ of the respondents were married and a similar percentage $(67.1 \%)$ were in employment. The average monthly income of the respondents was SR 5,232; $30.7 \%$ of them had a monthly income of less than SR 3,000 while 20.2\% earned from SR 3,000 to SR 6,000, 27.8\% of the respondents earned from SR 600,1 to SR 9,000 and the remainder (21.2\%) had a monthly income of more than SR 9,000. With regard to education, $27.8 \%$ of the respondents had had an elementary education (or lower) and a similar percentage had intermediate and secondary qualifications ( $27.1 \%$ and $27.3 \%$ respectively). $17.8 \%$ of the respondents had a university degree or above.

As regards the health-related variables of the respondents, the vast majority of those in the study sample (94.4\%) were registered with an $\mathrm{MOH}$ primary health care centre, about $38 \%$ reported that they had some sort of chronic illness and about three-quarter of them perceived their health status to be poor. Regarding medical insurance, only 19.3\% of respondents stated that they had health insurance coverage. 
Table 1. Frequency distribution according to individual-related variables.

\begin{tabular}{|c|c|c|}
\hline Variables & $\begin{array}{c}\text { Freq. } \\
N=410\end{array}$ & $(\%)$ \\
\hline \multicolumn{3}{|l|}{ Gender } \\
\hline Male & 231 & 56.3 \\
\hline Female & 179 & 43.7 \\
\hline \multicolumn{3}{|l|}{ Age $($ mean $=44.24$, S.D $=14.26)$} \\
\hline $18-30$ & 79 & 19.3 \\
\hline $31-40$ & 70 & 17.1 \\
\hline $41-50$ & 130 & 31.7 \\
\hline $51-60$ & 87 & 21.2 \\
\hline $60+$ & 44 & 10.7 \\
\hline \multicolumn{3}{|l|}{ Nationality } \\
\hline Saudi & 314 & 76.6 \\
\hline Non-Saudi & 96 & 23.4 \\
\hline \multicolumn{3}{|l|}{ Marital status } \\
\hline Married & 276 & 67.3 \\
\hline Unmarried & 134 & 32.7 \\
\hline \multicolumn{3}{|l|}{ Level of education $($ mean $=2.35$, S.D $=1.07)$} \\
\hline Elementary (1) & 114 & 27.8 \\
\hline Intermediate (2) & 111 & 27.1 \\
\hline Secondary (3) & 112 & 27.3 \\
\hline University or above (4) & 73 & 17.8 \\
\hline \multicolumn{3}{|l|}{ Employment status } \\
\hline Employed & 275 & 67.1 \\
\hline Unemployed & 135 & 32.9 \\
\hline \multicolumn{3}{|l|}{ Monthly income $($ mean $=5,232, S . D=2,381)$} \\
\hline Less than 3,000 & 126 & 30.7 \\
\hline $3,000-6,000$ & 83 & 20.2 \\
\hline $6,001-9,000$ & 114 & 27.8 \\
\hline More than 9,000 & 87 & 21.2 \\
\hline \multicolumn{3}{|l|}{ Registration with PHC } \\
\hline Yes & 387 & 94.4 \\
\hline No & 23 & 5.6 \\
\hline \multicolumn{3}{|l|}{ Health status $($ mean $=1.72, S . D=0.45)$} \\
\hline Good (1) & 113 & 27.6 \\
\hline Poor (2) & 297 & 72.4 \\
\hline \multicolumn{3}{|l|}{ Chronic illness } \\
\hline Yes & 158 & 38.5 \\
\hline No & 252 & 61.5 \\
\hline \multicolumn{3}{|l|}{ Health insurance } \\
\hline Yes & 79 & 19.3 \\
\hline No & 331 & 80.7 \\
\hline
\end{tabular}

Table 2. shows the responses when the participants in the study sample were asked to report on the importance of a number of provider-related variables which had influenced their decision to choose the present health care facility (i.e., the health facility where the patients were given the questionnaires). Patients' responses to the question: which of the following items influenced your choice to attend this health facility (note that the study took place in both public and private health care facilities), were gathered on a four-point Likert scale (with $1=$ Not important at all, $2=$ Not important, 3=Important and 4=Very important). Due to small responses on the scale for some variables, combination and recoding for these variables was made as follows: $1=$ Not important at all and $2=$ Not important were combined and recoded as ' $1=$ Not important. In addition, 3=Important' and ' $4=$ Very important' were combined and 
recoded as ' $2=$ Important'. The table also shows the frequency of responses, their means and their standard deviation.

TABLE 2. Frequency distribution according to provider-related variables.

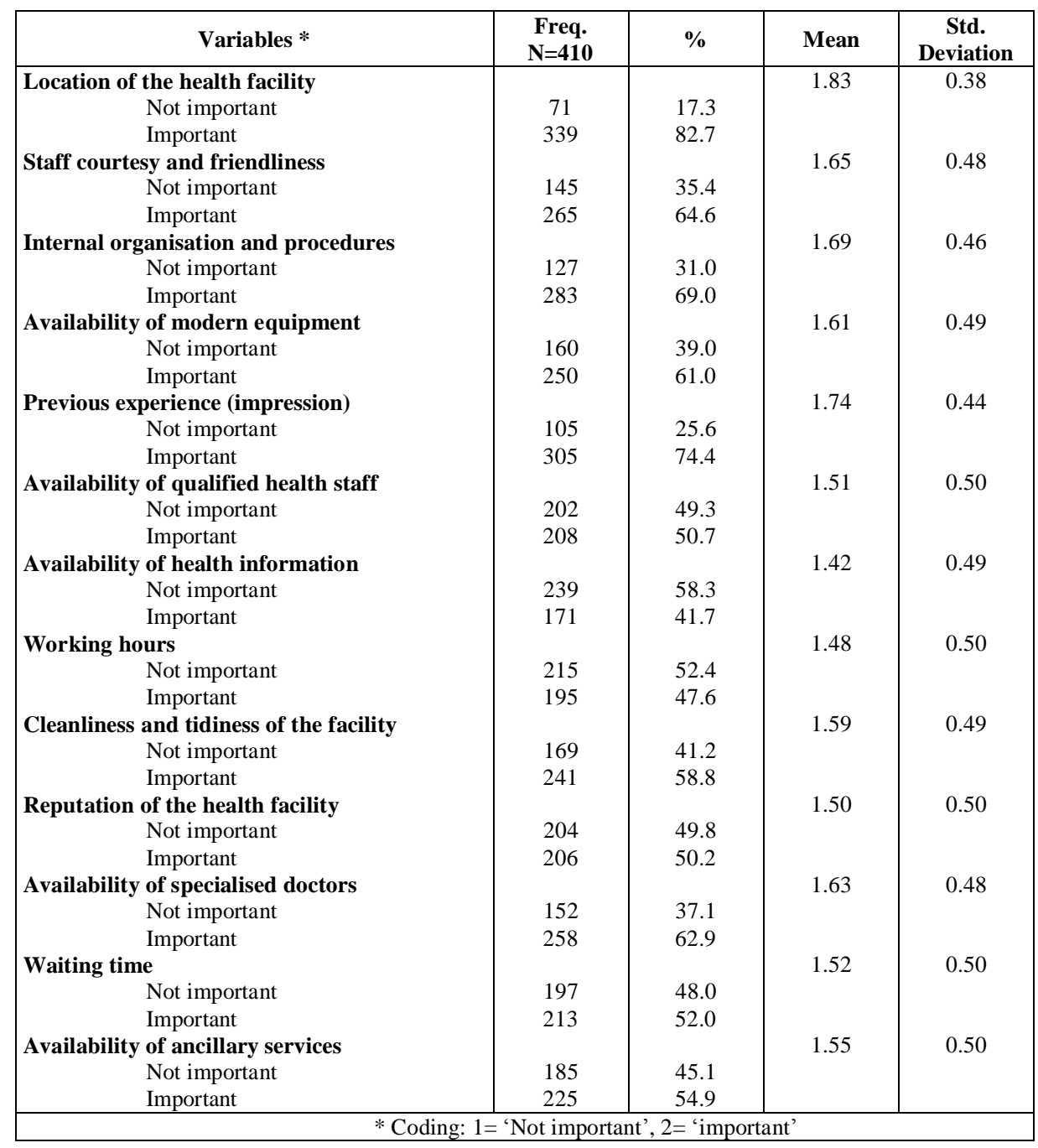

Table 3. shows a breakdown of the patient-related variables according to the chosen health facility (public $v s$. private health facilities). The table indicates that the respondents in the study sample were fairly heterogeneous on a variety of sociodemographic and health-related variables. Gender, age, nationality, education, employment, income and self-reported health status were found to associate significantly with the chosen type of health facility $(\mathrm{P}<0.001)$. The availability of health insurance to the patient was found to be significantly associated with the type of health care site chosen $(\mathrm{P}<0.05)$. 
TABLE 3. Patients-related variables for public and private health facility users.

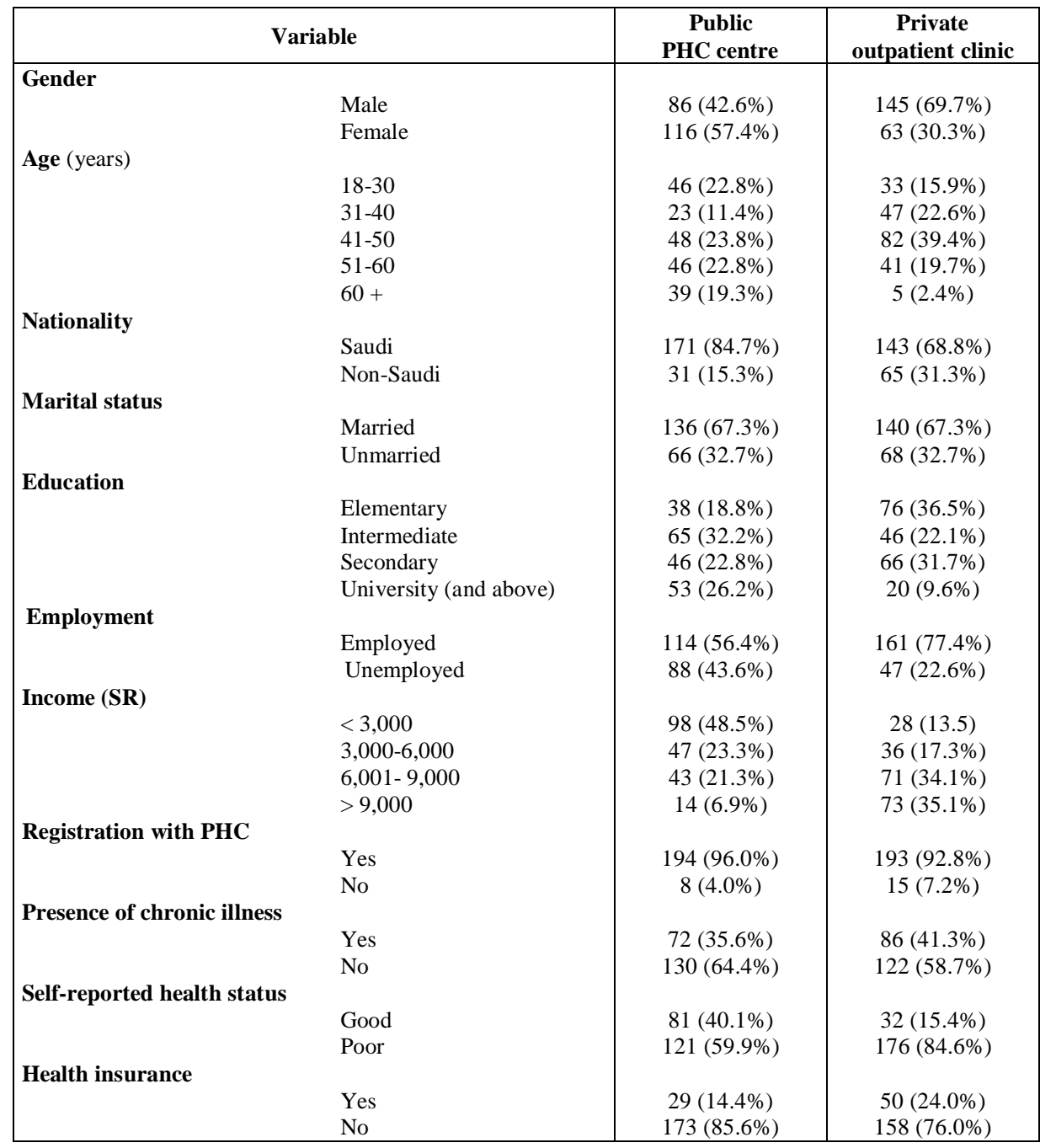

Table 4. shows a breakdown of the provider-related variables for respondents attending both public and private health facilities. The location of the health facility, courtesy of staff, opening hours, reputation of the health facility, length of waiting time, the availability of modern equipment, the availability of qualified health staff and the availability of a specialist doctor were significantly associated with the utilisation) of the type of health facility at $\mathrm{P}<0.001$. Further, the cleanliness of the health facility, the availability of information about patients' health and the availability of ancillary and diagnostic services were significantly associated with the utilisation of type of health care facility at $\mathrm{P}<0.05$. 
TABLE 4. Provider-related variables for public and private health facility users.

\begin{tabular}{|c|c|c|}
\hline Variables & $\begin{array}{c}\text { Public } \\
\text { PHC centre }\end{array}$ & $\begin{array}{c}\text { Private } \\
\text { Outpatient clinic }\end{array}$ \\
\hline \multicolumn{3}{|l|}{ Location of the health facility } \\
\hline Not important & $18(8.9 \%)$ & $53(25.5 \%)$ \\
\hline Important & $184(91.1 \%)$ & $155(74.5 \%)$ \\
\hline \multicolumn{3}{|l|}{ Staff courtesy and friendship } \\
\hline Not important & $88(43.6 \%)$ & $57(27.4 \%)$ \\
\hline Important & $114(56.4 \%)$ & $151(72.6 \%)$ \\
\hline \multicolumn{3}{|l|}{ Internal organisation and procedures } \\
\hline Not important & $69(34.2 \%)$ & $58(27.9 \%)$ \\
\hline Important & $133(65.8 \%)$ & $150(72.1 \%)$ \\
\hline \multicolumn{3}{|l|}{ Availability of modern equipment } \\
\hline Not important & $104(51.5 \%)$ & $56(26.9 \%)$ \\
\hline Important & $98(48.5 \%)$ & $152(73.1 \%)$ \\
\hline \multicolumn{3}{|l|}{ Cleanliness and tidiness of the facility } \\
\hline Not important & $54(26.7 \%)$ & $28(13.5 \%)$ \\
\hline Important & $148(73.3 \%)$ & $180(86.5 \%)$ \\
\hline \multicolumn{3}{|l|}{ Availability of qualified health staff } \\
\hline Not important & $118(58.4 \%)$ & $84(40.4 \%)$ \\
\hline Important & $84(41.6 \%)$ & $124(59.6 \%)$ \\
\hline \multicolumn{3}{|l|}{ Availability of health information } \\
\hline Not important & $129(63.9 \%)$ & $110(52.9 \%)$ \\
\hline Important & $73(36.1 \%)$ & $98(47.1 \%)$ \\
\hline \multicolumn{3}{|l|}{ Working hours } \\
\hline Not important & $138(68.3 \%)$ & $77(37.0 \%)$ \\
\hline Important & $64(31.7 \%)$ & $131(63.0 \%)$ \\
\hline \multicolumn{3}{|l|}{ Previous experience (or impression) } \\
\hline Not important & $105(52.0 \%)$ & $64(30.8 \%)$ \\
\hline Important & $97(48.0 \%)$ & $144(69.2 \%)$ \\
\hline \multicolumn{3}{|l|}{ Reputation of the health facility } \\
\hline Not important & $136(67.3 \%)$ & $68(32.7 \%)$ \\
\hline Important & $66(32.7 \%)$ & $140(67.3 \%)$ \\
\hline \multicolumn{3}{|l|}{ Availability of specialised doctors } \\
\hline Not important & $92(45.5 \%)$ & $60(28.8 \%)$ \\
\hline Important & $110(54.5 \%)$ & $148(71.2 \%)$ \\
\hline \multicolumn{3}{|l|}{ Waiting time } \\
\hline Not important & $137(67.8 \%)$ & $60(28.8 \%)$ \\
\hline Important & $65(32.2 \%)$ & $148(71.2 \%)$ \\
\hline \multicolumn{3}{|l|}{ Availability of ancillary services } \\
\hline Not important & $102(50.5 \%)$ & $83(39.9 \%)$ \\
\hline Important & $100(49.5 \%)$ & $125(60.1 \%)$ \\
\hline
\end{tabular}

\section{Multivariate Analysis}

To examine the combined effects of the independent variables, a multivariate statistical analysis is considered the most appropriate method to use. Therefore, binary logistic regression was used to determine the model which would distinguish between patients who used a public PHC and those who used a private outpatient clinic.

Table 5. presents a summary of 'backwards' stepwise (Wald's) results of logistic regression on all patients using both the public PHC centre and the private outpatient clinics. A large value of the Wald test (or a small p-value) is an indication that the variables are useful and should be added in the classification of patients (those who used the public PHC centre and those who used the private outpatient clinics). That is, the higher the Wald value, the more the variables differ between patients who used the 
public PHC centre and those who used the private outpatient clinics. As shown in the table, out of the 24 independent variables, 13 variables entered the logistic regression model, of which 11 have a significant effect on the dependent variable (the utilisation of the type of health facility). The magnitude of these 11 variables is shown in Table 5 and these variables reveal evidence of a significant difference between patients who used the public PHC centre and those who used the private outpatient clinics.

TABLE 5. Variables 'entered' the binary logistic regression analysis.

\begin{tabular}{|c|c|c|c|c|}
\hline Variables & $\begin{array}{c}\text { Beta } \\
\text { coefficient }\end{array}$ & S.E. & Wald & Sig. \\
\hline \multicolumn{5}{|l|}{ Individual-related variables } \\
\hline Gender & -1.144 & 0.335 & 11.637 & $0.001 *$ \\
\hline Education & -0.737 & 0.176 & 17.529 & $0.000 * *$ \\
\hline Income & 1.157 & 0.161 & 51.920 & $0.000 * *$ \\
\hline Nationality & 0.791 & 0.381 & 4.308 & $0.038 *$ \\
\hline Health status & 3.102 & 0.498 & 38.819 & $0.000 * *$ \\
\hline Health insurance & -1.123 & 0.407 & 7.637 & $0.006 *$ \\
\hline \multicolumn{5}{|l|}{ Provider-related variables } \\
\hline Location of health facility & -2.753 & 0.491 & 31.369 & $0.000 * *$ \\
\hline Waiting time & 2.272 & 0.488 & 21.690 & $0.000 * *$ \\
\hline Working hours & 0.925 & 0.341 & 7.356 & $0.007 *$ \\
\hline Availability of specialised doctors & 0.879 & 0.379 & 5.370 & $0.020 *$ \\
\hline Availability of ancillary facilities & -1.783 & 0.482 & 13.672 & $0.000 * *$ \\
\hline $\begin{array}{l}\text { Availability of information to } \\
\text { patients }\end{array}$ & -0.714 & 0.408 & 3.059 & $0.080 \mathrm{~ns}$ \\
\hline $\begin{array}{l}\text { Cleanliness and tidiness of the health } \\
\text { facility }\end{array}$ & 0.669 & 0.390 & 2.943 & $0.086 \mathrm{~ns}$ \\
\hline
\end{tabular}

Table 6. lists the patient-related variables entered in the logistic regression according to their importance and shows that 'patient's income' is the most important variable, followed by the perceived 'health status' of the patient and 'patient's education'. All these three variables are statistically significant at $\mathrm{P}<0.001$ and accounted for 51.9, 38.8 and 7.4 in the Wald test respectively. Other significant patient-related variables can be seen in the table.

Table 6 also shows the provider-related variables according to their importance in the logistic regression. Location of the health facility is the most important variable, followed by 'waiting time' and the availability of ancillary facilities. All these three variables are statistically significant at $\mathrm{P}<0.001$ and accounted for about 31.4, 21.7 and 13.7 in the Wald test respectively. Other significant provider-variables can be seen in the table. 
TABLE 6. Significant variables resulted from the logistic regression.

\begin{tabular}{|c|c|c|c|c|c|}
\hline $\begin{array}{c}\text { Relative } \\
\text { importance }\end{array}$ & Variables & $\begin{array}{c}\text { Beta } \\
\text { coefficient }\end{array}$ & S.E. & Wald & Sig. \\
\hline & Individual-related variables & & & & \\
\hline 1 & Income & 1.157 & 0.161 & 51.920 & $0.000 * *$ \\
\hline 2 & Health status & 3.102 & 0.498 & 38.819 & $0.000 * *$ \\
\hline 3 & Education & -0.737 & 0.176 & 17.529 & $0.000 * *$ \\
\hline 4 & Gender & -1.144 & 0.335 & 11.637 & $0.001 *$ \\
\hline 5 & Health insurance & -1.123 & 0.407 & 7.637 & $0.006 *$ \\
\hline \multirow[t]{2}{*}{6} & Nationality & 0.791 & 0.381 & 4.308 & $0.038 *$ \\
\hline & Provider-related variables & & & & \\
\hline 1 & Location of health facility & -2.753 & 0.491 & 31.369 & $0.000 * *$ \\
\hline 2 & Waiting time & 2.272 & 0.488 & 21.690 & $0.000 * *$ \\
\hline 3 & Availability of ancillary facilities & -1.783 & 0.482 & 13.672 & $0.000 * *$ \\
\hline 4 & Working hours & 0.925 & 0.341 & 7.356 & $0.007 *$ \\
\hline 5 & Availability of specialised doctors & 0.879 & 0.379 & 5.370 & $0.020 *$ \\
\hline \multirow[t]{2}{*}{6} & Cleanliness and tidiness of the health & & & & \\
\hline & facility & 0.669 & 0.390 & 2.943 & $0.086 \mathrm{~ns}$ \\
\hline 7 & Availability of information to patients & -0.714 & 0.408 & 3.059 & $0.080 \mathrm{~ns}$ \\
\hline
\end{tabular}

\section{Discussion}

This study was conducted to examine the utilisation of type of health care facility (a public vs. a private health facility) and to explore the factors associated with such utilisation, about which minimal information is currently available in Saudi Arabia. To do this, many factors were used, relating both to the individuals seeking health care and the facilities providing such care. The study identified several significant factors associated with the utilisation of a public or a private health care which could contribute to 'health planners' and 'decision makers' understanding of the provision and utilisation of health services in Saudi Arabia.

In this study, the results of the multivariate analyses show that a variety of individual and provider variables strongly influenced the choice of site of health care. Among the individual-related variables which were found significantly associated with the use of public or private health care were income, perceived health status, level of education, gender, health insurance and nationality. In addition, a number of providerrelated variables were found significantly influence the use public or private health care including health facility location, waiting time, the availability of ancillary services, opening hours and the availability of specialised doctors. In general, the results reported here broadly support many of the previous studies on the utilisation of public and private health care facilities.

\section{Individual-Related Variables}

The results of this study show that males were more likely to use private outpatient clinics than females, since more than two-thirds of the respondents who chose private outpatient clinics were males. This is possibly because males are more mobile than females and they may travel to whichever facility they wish. Another interpretation for this finding is that since about three-quarters (74\%) of males in the study sample were employed, they may have more ability to pay for their health care than females. In addition, the fact that there were more male respondents in the study sample may allow 
another interpretation of this finding. This finding contradicts the results reported by AlOmar and Saeed (1999). In their study, although there was a higher percentage of male patients than female using the private outpatient clinics, gender is not found to be a discriminating factor in the choice between public and private health facilities. However, the findings reported in the present study are in agreement with those of the studies conducted in Riyadh by Saeed (1998) and Al-Doghaither et al., (2003), who find that males were more likely to utilise private health facilities. The authors suggest that males are less likely to tolerate the long waiting times in government facilities.

Individuals with higher income were more likely to use private outpatient clinics. This finding is congruent with other studies which suggest that individuals with higher income tend to use private doctors (Al-Doghaither et al., 2003; Andaleeb, 2000; Saeed, 1998). Like income, the possession of health insurance makes individuals more likely to use a private outpatient clinic, according to the present study. This finding is in line with the results reported earlier by Saeed (1998). This author finds that the factor termed 'health insurance coverage' was found as a discriminating variable in the choice between public and private health care facilities. However, those with a limited income or without health insurance coverage may consider it necessary to go to a public PHC centre, probably to avoid the additional fees for being treated there. It has been reported that the ability to pay is an important factor for the utilisation of health care services and that people with a higher income are in a better position to pay privately if they choose to use alternative treatments (Kelner and Wellman 1997). Thus, this study provides evidence that education, income and health insurance represent different dimensions of social class, all of which are positively associated with private outpatient clinic use in this study population.

As with income and health insurance, education had a significant, positive effect on the choice of a private outpatient clinic. In the regression analysis, education emerges as a very important factor, implying that the more educated the patients, the more likely they are to choose to use a private outpatient clinic. One possible interpretation for this finding is that the standards of health care offered in public PHC centres do not meet their expectations. Another explanation is that education might be acting as a proxy for better knowledge and understanding of where to seek medical help among several alternatives available to patients. Al-Omar and Saeed (1999), for instance, indicate that dissatisfaction with $\mathrm{MOH}$ facilities among educated patients may motivate them to choose private facilities.

When asked about their health status, more of the respondents in the private outpatient clinics $(84.6 \%)$ rated their health status as 'poor' than the patients who used public PHC centre $(59.9 \%)$. Thus, patients who chose private outpatient clinics were more likely to assess their health status as poor than were the users of public PHC centre. There is support from other studies for this finding. Saeed (1998), for example, finds that a significantly higher percentage of patients who chose private hospitals perceived their health status as poor. A possible explanation why those who perceived their health status to be poor would choose a private outpatient clinic is the well-known fact that public PHC centres are more overcrowded than private outpatient clinics and consequently they choose private outpatient clinics where they may obtain speedy service. In fact, Saeed (1998) indicates in his study that government facilities are 
associated with long waiting times and this motivates people with poor health status or with chronic illness to go to private facilities. The results of the present study should be interpreted with caution because of the fact that data were reported on the basis of the respondents' assessments, not the doctors'.

Contrary to expectation, being 'registered' with a public PHC centre was found not statistically significant in the regression analysis. The recent medical literature on the utilisation of health services, however, indicates the importance of having a regular source of care in order to maintain the health of individuals and communities (Love et al., 2004; Sellick et al., 2003; Wilkie, 2003; Wyke, 2003). In this study, the vast majority of patients who chose both public and private health facilities were registered with a public PHC centre. This finding indicates that simply providing people with free PHC services does not ensure that the use of private health care facilities will necessarily decrease. Further, this finding suggests that the reasons why some persons choose to use a private outpatient clinic for their care has less to do with an absolute lack of access to public PHC than perhaps with issues of the accessibility, availability and quality of services provided in these facilities.

\section{Provider-Related Variables}

The fact that there was a significant difference in a number of variables in the utilisation of a public or private health care facility suggests that the two types of settings were not perceived as being equivalent and that each type might offer potential benefits. For example, the opening hours of the health care facilities was found to be an important factor in choosing where to obtain health care. In this study, two-thirds of respondents who chose the private outpatient clinics reported that the working hours of these health facilities were important in encouraging them to attend. In Saudi Arabia, the public health care sector suffers from the disadvantages that PHC centres are open at fixed times during the day and the week, whereas private health facilities are often open later in the evening and at the weekend as well, possibly to response to the demand for extending hours of health care.

The present study indicates that more than $70 \%$ of the respondents surveyed in the private outpatient clinics reported that they attend these facilities because of the length of time they must wait in the public PHC centres. This finding concurs with that reported in a number of studies conducted in Saudi Arabia. For example, the study carried out by Al-Doghaither et al., (2003) reports that the time factor (e.g. the working hours and waiting times) was important in influencing patients' choice of type of health facility. Similarly, Umeh (1994) indicates that people in Saudi Arabia attend private facilities because of their availability after the normal working hours of the public sector and because of their 'speed' in providing services. El-Shabrawy and Eisa (1993) find in their study that almost two-thirds of the dissatisfied patients complained about the length of waiting time in the public PHC facilities. A study in the United Kingdom by Gulliford et al., (2002) reports that waiting times may sometimes be indicative of organisational barriers to access which may result from the inefficient use of existing capacity or a failure to design services around the needs of patients. Previous research, however, indicates that 'waiting time' has a significant influence on the use of and satisfaction with health services (Ajayi, 2002; Andersson and Karlberg, 2001; Arnesen et al., 2002; Caris-Verhallen and Kerkstra, 2001; Kmietowicz, 1999). 
In this study, patients were asked whether the availability of ancillary services and facilities (such as x-ray machines and laboratories) in health care facilities might have affected their decision to attend the health care facility. More than $60 \%$ of respondents in the private outpatient clinics viewed this factor as important (or very important) in encouraging them to attend the private outpatient clinics. In the multivariate analysis, it was found that the availability of ancillary services was a significant factor in distinguishing between public and private health care users. This finding may not be surprising, since the $\mathrm{MOH}$ recent statistics show that out of the 1,792 public PHC centres in Saudi Arabia only 411 (23\%) have X-ray equipment and 1,081 (60\%) have laboratories (MOH, 2002). This finding concurs with previous research in Saudi Arabia which reports that problems faced by patients who present to government PHC centres include insufficient drug supplies, inadequate and delayed laboratory and radiological services (Al-Doghaither and Saeed, 2000; Al-Faris et al., 1996) and delays in the results of investigative procedures (Al-Faris et al., 1996).

Access to health facilities as measured by their location is known to be an important factor in choosing the site of health care. In this study, the distance between a respondent's home and the health provider was found to be a significant factor in the logistic regression analysis. The results show that more than $90 \%$ of respondents who chose to use public PHC centre cited the PHC location as important in their choice of the type of health care facility. This indicates that a patient who reported this factor as important was more likely to choose a public PHC centre. This finding may indicate the relevant distribution of public PHC centres in the Kingdom, though further research is needed to confirm this. According to $\mathrm{MOH}$ annual reports, $98 \%$ of the population have access to health care services, including public PHC and hospital services.

In fact, much research on the utilisation of health services has found that the proximity to health facilities affects a patient's decision to attend these facilities. Distance has been found to be inversely related to health facilities in studies in the UK (Hull et al., 1997; Walsh, 1990), the United States (Padgett and Brodsky, 1992), New Zealand (Kljakovic et al., 1981), Sweden (Magnusson, 1980) and Canada (Beland et al., 1998; Ingram et al, 1978). These studies suggest that the travelling distance was a major factor and that patients who lived close to the health care facility were more likely to attend it than other more distant facilities.

The present study, however, finds evidence that the nearby public PHC centre does not mean that it will be used by most of the patients living nearby. Results here show that the patients who chose a private outpatient clinic did not give as much importance to the location as did those who chose a public PHC centre. This means that these private clients may travel longer in order to satisfy their health need. It is possible that other factors were involved in the process of choosing the site of health care. This may include the type of health problem, the perception among patients of waiting times, quality of service and the availability of other facilities which they thought necessary for them. Basu (1982) indicates that such factors seem more important than the location of the health facility. Thus, in this study, the fact that public PHC centres suffer from a shortage of physicians, nurses and ancillary facilities may partly explain why some patients travel further to private outpatient clinics. Umeh (1994) comments on the quality of health services and reports that the private sector in Saudi Arabia provides 
hotel-like accommodation and amenities and extra ancillary and diagnostic services to persuade patients to use to their services. Further, Umeh indicates that health services provided to the public without payment may be judged lower in quality. Thus, it seems that health care location is not a major problem and the population may be seeking care from the most 'attractive' facilities.

When the utilisation of public and private health facilities according to the respondents' nationality was analysed, it was found that non-Saudis were more likely to use private outpatient clinics than Saudis. This finding agrees with the results reported by Saeed (1998), who studied the factors affecting patients' choice of hospital in Riyadh and found that nationality was not a discriminating factor in the choice between public and private facilities. The findings in our study may be explained by the fact that most of the adult non-Saudis in the country are workers and their employers are required to provide them with private health care (except for emergency cases). Thus, it is not surprising to find that a significantly higher percentage of the patients who chose the private outpatient clinics were non-Saudis.

Patients who identified the availability of a specialist doctor as 'important' in motivating them to attend a health facility were more likely to use a private outpatient clinic. This finding could be explained by the fact that in health care systems with restricted access to specialist care, such as that in Saudi Arabia, the only alternative source of care available to patients is either to go to an A\&E hospital department or to a private doctor. Another explanation for seeking health care from specialists could be attributed to the perception among patients of the seriousness and type of their complaint. These patients, possibly, felt it was no longer worthwhile to attempting to see their public PHC doctor or wait for referral if they believed that medical treatment was needed urgently for a particular condition. Studies conducted in the UK by Stewart et al., (1989) and Prince and Worth (1992) find that some patients had evaluated their own symptoms and on this basis made assumptions about the treatment and facilities required. An important point here is that, whether a specialised doctor was needed or not, in Saudi Arabia there is a lack of coordination, integration and feedback between private and public facilities, as well as between A\&E departments and PHC centres and patients may thus undergo repeated or unnecessary investigations and procedures in public PHC facilities in the future (as most of these patients were registered with a public PHC centre).

\section{Conclusion}

This paper contributes in several ways to the literature on health services utilisation. First, it presents evidence that individuals choose to use private outpatient clinics as a substitutive choice to the government's free PHC, particularly when people perceive public PHC centres to be less available or accessible. In other words, private outpatient clinics function as a "safety net," providing care to patients who do not have access to public PHC services or who perceive themselves to need such facilities. Second, this study indicates that private outpatient clinics are playing a significant role in the delivery of health services to a large segment of the population in Saudi Arabia. Third, it contributes to our understanding of potentially important explanatory variables which need to be considered in the planning and implementing of health care for a given society. Finally, the present study uses logistic regression to identify the combination of 
individual and provider variables which may influence the patient's choice of health care facility. Among the reasons for choosing this statistical technique was that, for heath policy, the important point is to understand what important factors determine the choice of health care alternatives.

Previous studies in the Kingdom of Saudi Arabia which have discussed the choice among health care facilities are limited in number and in the factors employed in these studies; possibly due to the fact that investigating such topics involves a variety of factors which are interrelated. The results of this study show that a number of individual and provider characteristics strongly influence the choice of a particular health care facility. In general the results reported here are broadly in line with those found in the literature, which suggests that a combination of these variables leads an individual to choose a particular health facility and not another. It should be noted here that these factors do not operate individually, but interact in a complex and varying manner.

This study helps us to understand the medical needs of the society and thus to provide better health care. The results suggest that gender, educational level, income, nationality, health status and the availability of health insurance were the most important factors among the individual-related variables. Further, the study suggests that waiting time, PHC location, the availability of ancillary services and opening/working hours were among the most important provider-related variables. These results indicate that patients are quite rational in the variables which they cite as 'important' in their utilisation of type of health facilities. Rational planning and allocation of resources require an understanding of the effects of different factors on the choice of site of care to allow a closer match in future between provision and need.

\section{Policy Implications and Recommendations}

Since the government regards primary health care as a priority, the specific recommendations which this study would like to offer, on the basis of the data analysis, are as follows. First, there is a need to remove several hurdles of accessibility to the public PHC centres as well as providing them with necessary facilities. As some public PHC facilities in Saudi Arabia at present may not be sufficiently available (due to limited working hours) or sufficiently responsive to meet routine health care needs (due to shortage of facilities), people have no alternative but to use private outpatient facilities (or other alternatives such as A\&E departments) in order to meet their health needs.

People whom are economically depressed or isolated from private medical services may use hospital emergency departments for problems which could be treated easily in PHC settings. Such behaviour not only creates additional workload for these acute facilities, but also prevents from getting proper treatment, since these facilities were not designed to provide primary care. Thus, extending the opening/working hours, tracking and reducing waiting time in public PHC centres and increasing the availability of their necessary ancillary and diagnostic services (e.g., as x-rays, laboratories and dental facilities) are important steps in increasing patient access to and satisfaction with these facilities. Moreover, this will ensure continuity and the use of preventive services which other facilities may not provide. 


\section{Limitations and Future Research}

There are always pros and cons for different methods of collecting data or selecting subjects, and no practical methodology can be implemented in the actual setting which will avoid all types of bias. Nevertheless, it is believed that the present results provide a valuable insight into some aspects which appear to influence the utilisation of public and private health facilities in Saudi Arabia. This research did not examine all the possible factors influencing the choice of health care facility because the choice between a public or a private health care facility is only the endpoint of a complex set of circumstances and decisions. A whole series of events may occur before a patient arrives at a health facility, starting from the patient 's first perception of his or her illness until the ultimate decision to use the particular health facility. These decisions are usually based on many interrelated variables which may include social, psychological, environmental, economic and other important factors which were not examined here. Therefore, it is suggested that future studies may include such variables which may affect the utilisation of public or private health care.

Another shortcoming which could have affected the results presented here is that the dependent variable used in this study was a dichotomous variable (public vs. private health facility) of the type of health facility sought. It is sometimes misleading to assume that people always make a dichotomous choice between private and public care; they may in fact choose other sites of care such as an A\&E department, private hospital or even 'self-care'. Other patients may utilise multiple sites of care for their health problems. This may have influenced the results reported here.

As with any questionnaire study, there was no way to ensure that the respondents' answers in the utilisation of site of care would reflect their actual behaviour. The results in this study are based on information reported by patients and are subject to the usual problems of bias associated with the accuracy of reporting on health care events. However, Petersen (1988) notes that it does not matter if the patient is right or wrong, for what is important is how the patients felt, even though the perception of reality on the part of their caregiver may be quite different. Finally, this study does not claim to be comprehensive; it was based on a single public PHC centre and two private outpatient clinics and thus, the results may have limited generalisability to other public PHC centres and private outpatient facilities. Thus, future research should attempt to address some of the concerns indicated in the limitations. Further investigation, perhaps of a larger number of public PHC centres and private outpatient clinics in the Kingdom, or using a different methodology and data analysis may elicit a greater volume of information on the utilisation of health care facility to increase and enrich the understanding of health services utilisation in the Kingdom of Saudi Arabia. 


\section{References}

Ajayi, I. (2002) Patients' waiting time at an outpatient clinic in Nigeria--can it be put to better use? Patient Education and Counseling, 47(2): 121-126.

Al-Doghaither, A., Abdelrhman, B., Saeed, A. and Magzoub, M.E. (2003) Factors Influencing Patient Choice of Hospitals in Riyadh, Saudi Arabia, The Journal of The Royal Society for the Promotion of Health, 123(2): 105-109.

Al-Doghaither, A. and Saeed, A. (2000) Consumers' satisfaction with primary health services in the city of Jeddah, Saudi Arabia, Saudi Medical Journal, 21(5): 447-454.

Al-Faris, E., Khoja, T., Falouda, M. and Saeed, A. (1996) Patients' satisfaction with accessibility and services offered in Riyadh health centres, Saudi Medical Journal, 17(1): 11-17.

Al-Mazrou, Y., Khoja, T. and Rao, M. (1995) Health services in Saudi Arabia, Proceedings of the Royal College of Physicians of Edinburgh, 25: 263-266.

Al-Omar, B. and Saeed, K. (1999) Factors influencing patient's utilization of primary health care providers in Saudi Arabia, Journal of Family and Community Medicine, 6(1) 31-39.

Andaleeb, S. (2000) Public and private hospitals in Bangladesh: service quality and predictors of hospital choice, Health Policy and Planning, 15(1): 95-102.

Andersen, R. (1995) Revisiting the behavioral model and access to medical care: Does it matter? Journal of Health and Social Behavior, 36(1): 1-10.

Andersen, R. and Newman, J. (1973) Societal and individual determinants of medical care utilization, Milbank Memorial Fund Quarterly, 51(1): 95-124.

Andersson, G. and Karlberg, I. (2001) Lack of integration, and seasonal variations in demand explained performance problems and waiting times for patients at emergency departments: a 3 years evaluation of the shift of responsibility between primary and secondary care by closure of two acute hospitals, Health Policy, 55: 187-208.

Arnesen, K., Erikssen, J. and Stavem, K. (2002) Gender and socioeconomic status as determinants of waiting time for inpatient surgery in a system with implicit queue management, Health Policy, 62: 329-341.

Basu, R. (1982) Use of emergency room facilities in a rural area: A spatial analysis, Social Science and Medicine, 16: 75-84.

Beland, F., Lemay, A. and Boucher, M. (1998) Patterns of visits to hospital-based emergency rooms, Social Science and Medicine, 47(2): 165-179.

Benyoussef, A. and Wessen, F. (1974) Health care in developing countries, Social Science and Medicine, 11: 399-408.

Bice, T. and White, K. (1969) Factors related to the use of health services: An International comparative study, Medical Care, 7(2): 124-133.

Caris-Verhallen, W. and Kerkstra, A. (2001) Continuity of care for patients on a waiting list for institutional long-term care, Health and Social Care in the Community, 9(1): 1-9.

Cummings, K., Becker, M. and Maile, M. (1980) Bringing the models together: an empirical approach to combining variables used to explain health actions, Journal of Behavioral Medicine, 3(2): 123-145.

Davidson, S. (1978) Understanding the growth of emergency department utilization, Medical Care, 16(2): 122-131.

El-Shabrawy, A. and Eisa, A. (1993) A study of patient satisfaction with primary health care services in Saudi Arabia, Journal of Community Health, 18(1): 49-54.

Field, K. and Eisa, D. (2001) Socio-economic and locational determinants of accessibility and utilization of primary health-care, Health and Social Care in the Community, 9(5): 294308.

Galvin, M. and Fan, M. (1975) The utilization of physicians' services in Los Angeles county, Journal of Health and Social Behavior, 16(1): 74-94.

Gulliford, M., Figueroa-Munoz, Morgan, M., Hughes, D., Gibson, B., Beech, R. and Hudson, M. (2002) What does 'access to health care' mean? Journal of Health Services Research and Policy, 7(3): 186-188. 
Gulliford, M. and Mahabir, D. (2001) Utilisation of private care by public primary care clinic attenders with diabetes: relationship to health status and social factors, Social Science and Medicine, 53: 1045-156.

Hull, S., Jones, I. and Moser, K. (1997) Factors influencing the attendance rate at accident and emergency departments in East London: the contributions of practice organization, population characteristics and distance, Journal of Health Services Research and Policy, 2(1): 6-13.

Ingram, D., Clarke, D. and Murdie, R. (1978) Distance and the decision to visit an emergency department, Social Science and Medicine, 12: 55-62.

Kelner, M. and Wellman, B. (1997) Health care and consumer choice: Medical and alternative therapies, Social Science and Medicine, 45(2): 203-212.

Kljakovic, M., Allan, B. and Reinken, J. (1981) Why skip the general practitioner and go to the accident and emergency department? New Zealand Medical Journal, 93: 49-52.

Kmietowicz, Z. (1999) Waiting times in British casualty departments remain too long, British Medical Journal, 318: 351.

Leavitt, F. (1979) The Health Belief Model and utilization of ambulatory care services, Social Science and Medicine, 13A: 105-112.

Love, T., Dowell, A., Salmond, C. and Crampton, P. (2004) Quality indicators and variation in primary care: modelling GP referral patterns, Family Practice, 21(2): 160-165.

Magnusson, G. (1980) The role of proximity in the use of hospital emergency departments, Sociology of Health and Illness, 2: 202-214.

McKinlay, J. (1972) Some approaches and problems in the study of the use of services: An overview, Journal of Health and Social Behavior, 13(2): 115-152.

Mechanic, D. (1979) Correlates of physician utilization: Why do major multivariate studies of physician utilization find trivial psychosocial and organizational effects? Journal of Health and Social Behavior, 20: 387-396.

MOH (2002) Health Statistical Year Book: Ministry of Health, The Kingdom of Saudi Arabia.

Padgett, D. and Brodsky, B. (1992) Psychosocial factors influencing non-urgent use of the emergency room: A review of the literature and recommendations for research and improved service delivery, Social Science and Medicine, 35(9): 1189-1197.

Petersen, H. (1988) Measuring patient satisfaction: collecting useful data, Journal of Nursing Quality Assurance, 2(3): 25-35.

Prince, M. and Worth, C. (1992) A study of 'inappropriate' attendances to a paediatric Accident and Emergency Department, Journal of Public Medicine, 14(2): 177-182.

Purola, T. (1972) A systems approach to health and health policy, Medical Care, 10: 373-379.

Rosenstock, I. (1966) Why people use health services, Milbank Memorial Fund Quarterly, 44(Part II): 94-124.

Saeed, K. (1998) Factors affecting patients' choice of hospitals, Annals of Saudi Medicine, 18(5): 420-424.

Safer, M., Tharps, J., Jackson, T. and Leventhal, H. (1979) Determinants in three stages of delay in seeking care at a medical clinic, Medical Care, 17(1): 11-29.

Sebai, Z. (1987) Health services in Saudi Arabia, Saudi Medical Journal, 8(6): 541-548.

Sellick, K., Russell, S. and Beckmann, J. (2003) Primary nursing: An evaluation of its effects on patient perception of care and staff satisfaction, International Journal of Nursing Studies, 40: 545-551.

Shortell, S. (1988) Factors associated with the use of health services, In: Introduction to Health Services, New York: A Wily Medical Publication.

Stewart, M., Savage, J., Scott, M. and McClure, B. (1989) Primary Medical Care in a Paediatric Accident and Emergency Department, The Ulster Medical Journal, 58(1): 29-35.

Taeq, J. (1997) Multivariate Analysis Technique in Social Science Research: From Problem to Analysis, London: Sage Publication.

Umeh, J. (1994) Healthcare financing in the Kingdom of Saudi Arabia: A review of the options, World Hospitals, 31(2): 3-8. 
Walsh, M. (1990) Geographical factors and A\&E attendance, Nursing Standard, 5(8): 28-31.

Wan, T. and Soifer, S. (1974) Determinants of physician utilization: A casual analysis, Journal of Health and Social Behavior, 15: 100-108.

White-Means, I. and Thornton, C. (1989) Nonemergency visits to hospital emergency rooms: a comparison of blacks and whites, Milbank Quarterly, 67: 35-37.

Wilkie, P. (2003) Quality in general practice: patients and continuity of care, Quality in Primary Care, 11: 67-68.

Wolinsky, F. (1978) Assessing the effects of predisposing, enabling and illness-morbidity characteristics on health service utilization, Journal of Health and Social Behavior, 19(4): 384-396.

Wyke, S. (2003) Why people use primary care health services, Do we really need more research? Journal of Health Services Research and Policy, 8(1): 55-56. 


\title{
العو امل المؤثرة في الاستفادة من خدمات الرعاية الصحية الأولية

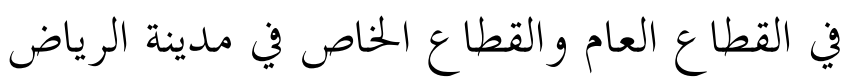

\author{
سعد بن عبد الله الغانم \\ أستاذ مساعد يلد الها

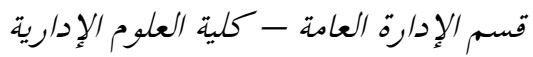

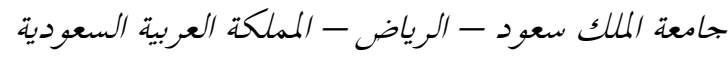

المستخلص. الهداف: تحديد المتغيرات المتوقعة التي تئثر على الاسـتفادة مـن خهـدمات

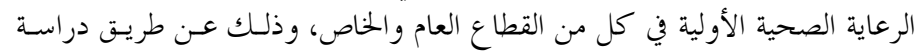

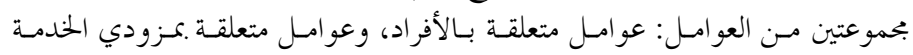

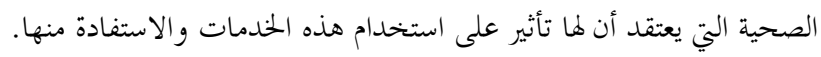

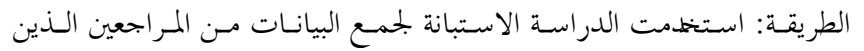

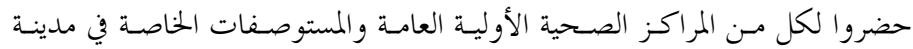

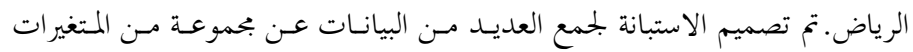

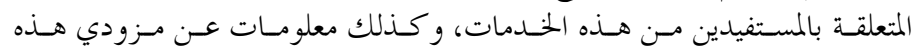

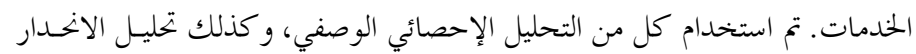

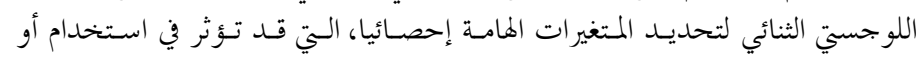

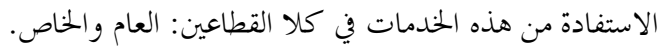

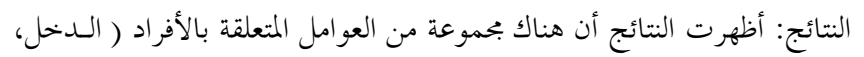

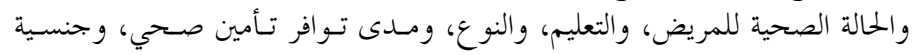

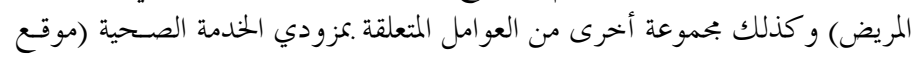

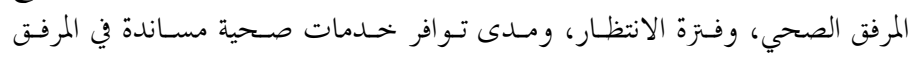

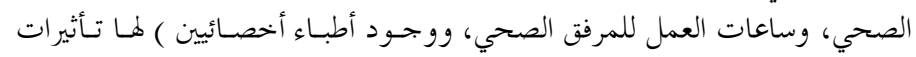

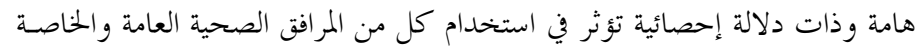

والاستفادة من خدماتها.

الخاتمة: تبرز الدراسة بحموعة من العوامل التي تدفع المرضى إلى استخدام المرافق

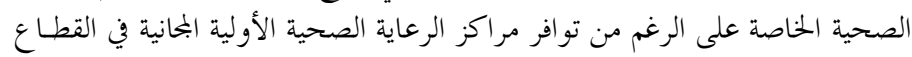

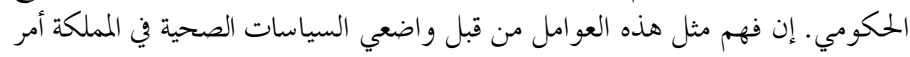

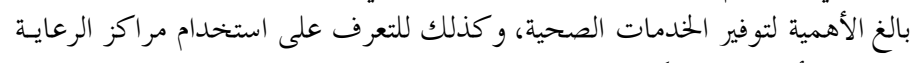

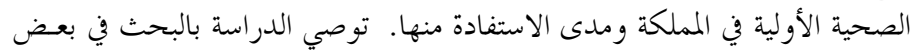
المواضيع الهامة، والتي يلزم تضمينها في البحوث المدلة العلمية المستقبلية. 